\title{
Microstructure and microanalysis studies of copper-nickel-tin alloys obtained by conventional powder metallurgy processing
}

\author{
W. A. Monteiro ${ }^{1,2, a}$, J. A. G. Carrió ${ }^{1, b}$, T. J. Masson ${ }^{1}$, C. D. Abreu ${ }^{1}$, \\ I. M. Marques ${ }^{1}$, L. C. E. da Silva ${ }^{2}$ \\ ${ }^{1}$ Presbyterian Mackenzie University, Rua da Consolação, 896, prédio 12, sala 406, Consolação, \\ CEP 01302-907, São Paulo - SP, Brazil \\ ${ }^{2}$ Institute of Energetic and Nuclear Researches (IPEN), São Paulo - SP, Brazil
}

atecnologia@mackenzie.br, bjgcarrio@mackenzie.br

\begin{abstract}
Keywords: copper-nickel-tin alloys, powder metallurgy, microstructure, structural characterization,
\end{abstract} electrical properties, mechanical properties.

\begin{abstract}
The aim of this article was to analyze the microstructural development in samples of $\mathrm{Cu}-$ Ni-Sn alloys (weight \%) obtained by powder metallurgy (P/M). The powders were mixed for $1 / 2$ hour. After this, they were pressed, in a cold uniaxial pressing $(1000 \mathrm{kPa})$. In the next step the specimens were sintered at temperatures varying from 650 up to $780^{\circ} \mathrm{C}$ under vacuum. Secondly, the samples were homogenized at $500^{\circ} \mathrm{C}$ for several special times. The alloys were characterized by optical microscopy, electrical conductivity and Vickers hardness. X rays powder diffraction data were collected for the sintered samples in order to a structural and microstructural analysis. The comparative analysis is based on the sintered density, densification parameter, hardness,
\end{abstract} macrostructures and microstructures of the samples.

\section{Introduction}

The copper has different applications in the modern society due to the excellent thermal conductivity, electric properties, resistance to the corrosion, resistance to the fatigue and good mechanical properties. Connectors, contact switches, heaters, valves, piping, pots for absorption of solar energy, radiators for automobiles, current driver, electronic driver, contact sheets, elements of thermostats are common applications. The copper can be used with high purity or with addition of alloy elements $(\mathrm{Ni}, \mathrm{Sn}, \mathrm{Be}, \mathrm{Pt}, \mathrm{Cr}, \mathrm{Nb}, \mathrm{Pb}, \mathrm{Al})$ that increase the principal properties [1-13].

The aim of this work is to obtain metallic alloys with high mechanical strength and high electric conductivity after adequate optimization of sintering and thermal treatments (powder metallurgy) followed by structural, microstructural, electrical and mechanical characterization of $\mathrm{Cu}-\mathrm{y} \% \mathrm{Ni}$ $\mathrm{x} \% \mathrm{Sn}$ alloys ( $\mathrm{x}$ and $\mathrm{y}$ has variable values in weight). Diverse types of products based on copper alloys can be manufactured through the process of powder metallurgy: porous, material filters, electric friction equipments, contacts and structural parts [14-18].

The alloy elements are added to copper with the intention to improve its resistance, ductility and thermal stability, without causing considerable damages on its form, electric and thermal conductivity and resistance to the corrosion, typical characteristic aspects of pure copper. The choice of these current alloys is related to the studies carried through previously in ternary alloys to similar copper nickel base the chosen ones [1-7].

The mechanical resistance in metallic alloys depends on the size, type, form and a regular distribution of precipitations, which is also fundamental to obtain an electrical conductivity similar to that of the copper matrix. To increase the mechanical resistance, ductility and formability keeping good electric conductivity of these alloys, have been used special thermal treatments as well as variations in the chemical composition. The main production of metallic materials is acquired by casting [1-8]. The contribution to the production of metallic parts by powder metallurgy is increased of consistent outline, supported for inestimable advantages. The list of benefits in the industrial processes of sintering is great and, not rare, surprises the coordinators of production of 
different industries that not yet had tried the technology and attend the explanation of specialists in the area [15-18].

The first one of the advantages is the cost reduction. This project looked for to get systematically, in scale of laboratory, copper-nickel ternary alloys production by powder metallurgy, concerning the maintenance of the electric and mechanical properties with the purpose of getting electric connectors of high performance or high mechanical damping [14-18].

This work attempt to obtain systematic stages of the sintering and homogenization of the ternary copper nickel alloys utilizing powder metallurgy. Being an alternative process to the conventional processes, the powder metallurgy also allows, in some cases, the structural manufacture of parts and components in economically and more advantageous conditions. Varied types of products of copper based alloys can be manufactured through the process of powder metallurgy for electric friction, contacts and structural parts. The alloy elements are added to copper with intention to improve the resistance, the ductility and the thermal stability, without causing considerable damages on its shape, electric and thermal conductivity, and also resistance to the corrosion [3-5].

Next to casting, mechanical forming and machining, powder metallurgy $(\mathrm{P} / \mathrm{M})$ technology is an important method of manufacturing metal parts. Undesirable characteristics of ingot based metals can be greatly reduced, and desired properties of metals which would normally not alloy easily can be achieved by combining different metal powders or mixtures of metal and non metal powders. The process of making powders, compressed them into useful shapes and then sintering them is costly, but the finished parts have some specific advantages over wrought or cast parts. The main advantages are: the possibility to make fine grained homogenous structures; the ability to form complicated shapes with close dimensional tolerances; and the ability to produce parts with a superior surface finish [14-18].

Costly machining processes are thus reduced or eliminated and consequently there is less scrap loss compared to other forming methods. It is therefore most economical to use powder metallurgy for the high volume production of small, intricately shaped, and/or very precise parts such as gears and links. In addition, the process offers the potential to produce a wide variety of alloys with different material properties such as high temperature toughness and hardness $[17,18]$.

\section{Experimental Conditions}

In research and failure analysis, metallography is a major tool used to develop new products and improve manufacturing processes. In addition to chemical analysis, quality control also includes physical methods for checking density, dimensional changes, flow rate etc. Powder production and mixing is a highly specialized and complex process which produces custom made powder mixes designed to satisfy the needs of a specific application. A good powder mix not only has the ability to produce the required properties of a specific alloy, but also needs to facilitate handling, compacting and sintering. Experimentally, for instance, the easy flow of powder and its capability to mix evenly with other powders is important for an even powder distribution before pressing, and ensures uniform properties of the finished part.

For the production of components the mixed powders are first compacted under high pressure has the geometrical feature of the finished component, but not its strength ("green" part). In order to develop the mechanical and physical properties of the material, metallurgical bonding has to take place through sintering at high temperature in a sintering furnace. The bonding occurs through diffusion between adjacent particles. To avoid oxidation, which would impair the inter-particle bonding, the sintering process is conducted in a protective atmosphere or vacuum. The bonding increases the density, and pressed and sintered powder metal parts generally contain residual porosity depending of the initial conditions.

As the density of the compacted and sintered part influences its key properties of strength, ductility and hardness, a specific porosity is critical. For process control, metallography is used to check porosity, non-metallic inclusions and cross-contamination. 
The as-pressed compacts were conventionally sintered in a high vacuum Carbolite furnace that had a hot zone of about $150 \mathrm{~mm}$. At the utilized composition the $\mathrm{Cu}-\mathrm{Ni}-\mathrm{Sn}$ alloys can be consolidated by solid state sintering. The most important conditions are presented in Table 1.

Table 1 - Sintering parameters of $\mathrm{Cu}-\mathrm{Ni}$-Sn

\begin{tabular}{|c|c|c|c|}
\hline Condition & \multicolumn{3}{|c|}{ Premixed } \\
\hline Compaction pressure & \multicolumn{3}{|c|}{$1000 \mathrm{kPa}$} \\
\hline $\begin{array}{c}\text { Chemical alloy } \\
\text { composition (wt \%) }\end{array}$ & \multicolumn{3}{|c|}{$\begin{array}{l}\mathrm{Cu}-0.5 \% \mathrm{Ni}-0.5 \% \mathrm{Sn} ; \mathrm{Cu}-1 \% \mathrm{Ni}-0.5 \% \mathrm{Sn} ; \mathrm{Cu}-1 \% \mathrm{Ni}-1 \% \mathrm{Sn} ; \mathrm{Cu}- \\
3 \% \mathrm{Ni}-3 \% \mathrm{Sn} ; \mathrm{Cu}-5 \% \mathrm{Ni}-5 \% \mathrm{Sn}\end{array}$} \\
\hline Sample dimensions & \multicolumn{3}{|c|}{ Cylinder diameter $\phi=10.2 \mathrm{~mm} \mathrm{e} \mathrm{h}=14.8 \mathrm{~mm}$} \\
\hline Sample weight & \multicolumn{3}{|c|}{$6.5 \mathrm{~g}$} \\
\hline \multirow{2}{*}{$\begin{array}{l}\text { Sintering temperature } \\
\text { and conditions }\end{array}$} & Sintering temperature, ${ }^{\circ} \mathrm{C}$ & $\begin{array}{l}\text { Condition for } \\
\text { premixed }\end{array}$ & $\begin{array}{l}\text { Vacuum } \\
\text { pressure }\end{array}$ \\
\hline & $650-800$ & Solid state sintering & $10^{-4}$ torr \\
\hline Sintering time, $\mathrm{s}$ & \multicolumn{3}{|c|}{$1.8 \times 10^{3}$ to $5.4 \times 10^{3}$} \\
\hline Homogenization time, $\mathrm{s}$ & \multicolumn{3}{|c|}{3,600 to 28,800} \\
\hline
\end{tabular}

Cold mounting of the sintered and homogenization samples was done by optical and hardness studies .The compacts were grinding with 400, 600, 800, 1000 and $1200 \mathrm{SiC}$ papers followed by fine wet wheel polishing (diamond or alumina pastes). Vickers hardness of the polished specimens was measured on a hardness tester (HXD 1000TM - Pantec, load of $100 \mathrm{~g}$ ). Acidic $\mathrm{FeCl}_{3}$ was used as the etchant. The microstructures of selected etched samples were observed in an optical microscope. Special samples for electrical conductivity studies were measured using an Agilent 4338B Milliohmmeter; $x$ rays powder diffraction data were collected with a conventional Rigaku Multiplex II diffractometer with a fixed monocromator. The experimental conditions were: $40 \mathrm{kV}$, $20 \mathrm{~mA}, 10^{\circ}<2 \theta<120^{\circ}, \Delta 2 \theta=0.02^{\circ}, \lambda_{\mathrm{CuK} \alpha}$, divergence slit $=0.5^{\circ}$, reception slit $=0.3 \mathrm{~mm}$ and step time $5 \mathrm{~s}$ [19].

\section{Results and Discussion}

The important data with copper-nickel-tin samples is shown in Table 2 concerning mixing, compacting, sintering, homogenizing treatments and also values of hardness and electrical conductivity.

Table 2 - Some mechanical and electrical properties of the copper-nickel-tin alloys obtained by powder metallurgy

\begin{tabular}{|l|c|c|c|c|c|c|}
\hline & \multicolumn{2}{|c|}{ Sintering } & \multicolumn{2}{l|}{ Homogenizing } & $\begin{array}{c}\text { Mechanical } \\
\text { Resistance }\end{array}$ & $\begin{array}{c}\text { Electrical } \\
\text { Conductivity }\end{array}$ \\
\hline $\mathrm{Cu}-\mathrm{Ni}-\mathrm{Sn}$ & $\mathrm{T}\left({ }^{\circ} \mathrm{C}\right)$ & $\mathrm{t}(\mathrm{s})$ & $\mathrm{T}\left({ }^{\circ} \mathrm{C}\right)$ & $\mathrm{t}(\mathrm{s})$ & $(\mathrm{MPa})$ & $(\%$ IACS $)$ \\
\hline $\mathrm{Cu}-0,5 \% \mathrm{Ni}-0,5 \% \mathrm{Sn}$ & 675 & 9900 & 500 & 172800 & 310 & 52 \\
\hline $\mathrm{Cu}-1 \% \mathrm{Ni}-1 \% \mathrm{Sn}$ & 700 & 5400 & 500 & 32400 & 540 & 37 \\
\hline $\mathrm{Cu}-1.0 \% \mathrm{Ni}-0.5 \% \mathrm{Sn}$ & 675 & 9900 & -- & -- & 308 & 38 \\
\hline $\mathrm{Cu}-1 \% \mathrm{Ni}-0.5 \% \mathrm{Sn}$ & 700 & 14400 & -- & -- & 300 & 34 \\
\hline
\end{tabular}


The mechanical resistance in metallic alloys depends on the precipitation distribution to obtain similar electrical conductivity of the copper (matrix). To increase the strength, ductility and formability keeping good electric conductivity of these alloys, have been used special thermal treatments as well as variations in the chemical composition. At the present time the mechanical strength (300 to $540 \mathrm{MPa}$ ) and electrical conductivity (34 to $52 \%$ IACS) values indicate a fine appliance for these alloys utilizing powder metallurgy as a substitute of conventional metallurgy processing.

The powder diffraction data indicate that the utilized amounts of dopants do not distorted the copper matrix structure significantly. No special broadening of the Bragg peaks was detected, which indicates that crystallite sizes are not affected.
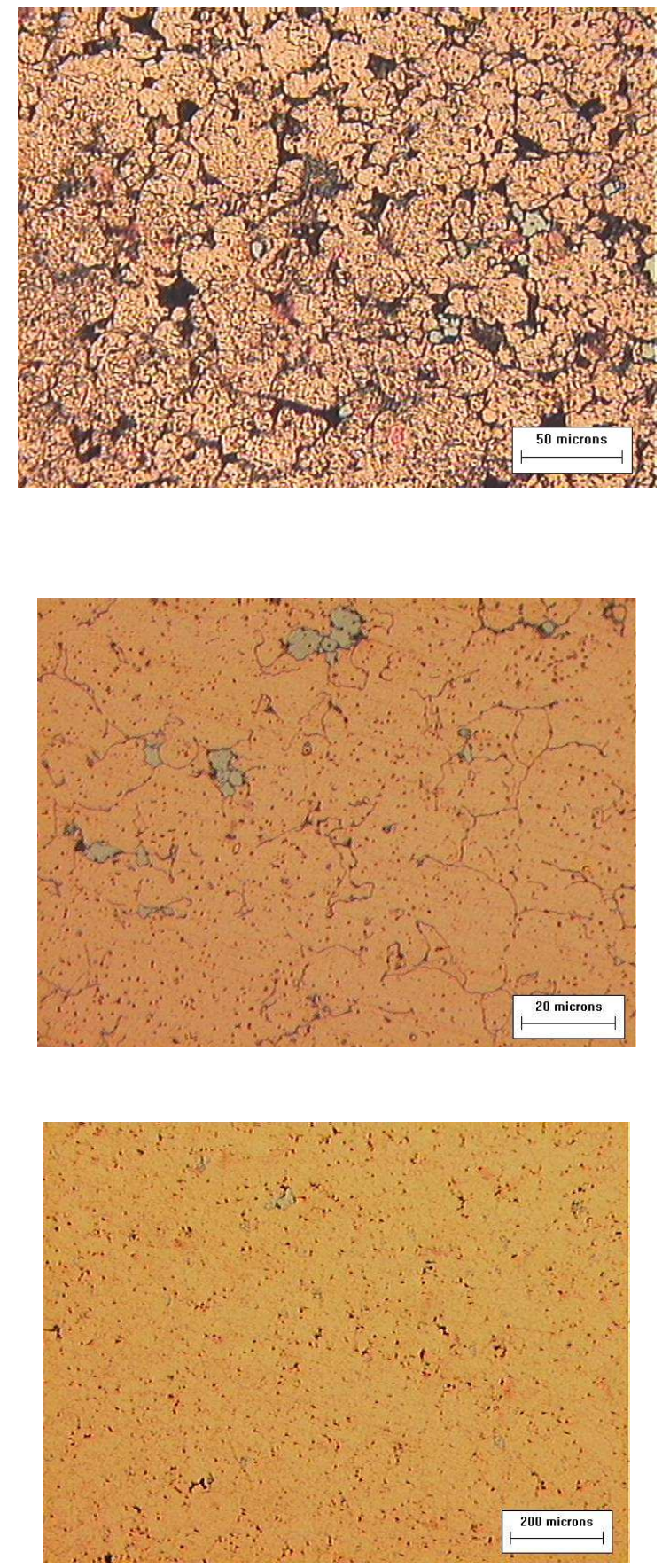

Fig.1- Optical micrograph of the alloy $\mathrm{Cu}$ $1.0 \% \mathrm{Ni}-0.5 \% \mathrm{Sn}$, cold compact $(250 \mathrm{MPa})$ and sintered at $650^{\circ} \mathrm{C}$ for $1200 \mathrm{~s}$

Fig.2- Optical micrograph of the alloy $\mathrm{Cu}$ $1 \% \mathrm{Ni}-0.5 \% \mathrm{Sn}$, cold compact $(250 \mathrm{MPa})$ and sintered at $650^{\circ} \mathrm{C}$ for $1200 \mathrm{~s}$

Figure 3- Optical micrograph of the alloy $\mathrm{Cu}$ $1 \% \mathrm{Ni}-1 \% \mathrm{Sn}$, cold compact $(250 \mathrm{MPa})$ and sintered at $650 \mathrm{C}$ for $5400 \mathrm{~s}$ 
Concerning the microstructural aspects, figures 1 to 3 show optical micrographs of some $\mathrm{Cu}-\mathrm{Ni}-\mathrm{Sn}$ alloys. Fine grained presences but with inadequate porosity and second phases show that a new homogenization treatments will be necessary to overcome this situation and also investigations with scanning and transmission electron microscopy to identify the presence of second phase on these alloys.

\section{Conclusion}

The practical powder metallurgy processing steps on the copper-nickel-tin alloys corroborate a firstrate mechanical strength (540 MPa) and electrical conductivity (52\%IACS) values that indicate a good quality employment for these alloys utilizing powder metallurgy instead conventional metallurgy processing. The possibility to look for and construct fine grained homogenous structures, the ability to produce parts with a superior surface finish and the ability to form complex shapes with close dimensional tolerances induces this metallurgical application.

\section{Acknowledgements}

The authors would like to thank to UPM (Mackpesquisa), CNPq and CAPES (Brazil) for financial support.

\section{References}

[1] J. Crane and J. Winter, Copper: Encyclopedia of Materials Science and Engineering, vol. 2, Ed. MB Bewer, Pergamon Press and the MIT Press (1986), p. 848 - 855.

[2] P. W. Taubenblat: Encyclopedia of Materials Science and Engineering, vol. 2, Ed. MB Bewer, Pergamon Press and the MIT Press (1986), p. 863-866.

[3] ASM Specialty Handbook: Copper and Copper Alloys, Metal, chapter 1, section 1, ASM International, (2001).

[4] C. R. Brooks: "Heat Treatment, Structure and Properties of Nonferrous Alloys", ed. ASM, Metals Park, 1988, chapter 8.

[5] A. Butts: "Copper, the Science and Technology of the Metal, its Alloys and Compounds", ed. Reinhold Publishing Corporation, New York, 1954, 3th printing 1960.

[6] G. Gosh, J. Kiyake and M. E. Fine: JOM (1997), p. 56.

[7] A. Rotem, D. Shechtman, and A. Rosen: Metall. Trans. A Vol. 19A (1988), p. 2279.

[8] D. Steiner, R. Beddoe, V. Gerold, G. Kostorz and R. Schmelczer: Scripta Metall. Vol. 17 (1983), p. 733.

[9] A. Guha: Development of a high-strength, high-conductivity $\mathrm{Cu}-\mathrm{Ni}-\mathrm{Be}$ Alloy, high conductivity Copper and Aluminum Alloys, eds. E. Ling and P. Taubenblat W., TMS - AIME Publ. (1984), p. 133-145.

[10] Y. Sakai, K. Inoue, and H. Maeda: Acta Metall. Mater. Vol. 43 (1995), p. 1517.

[11] W. A. Monteiro: in Proceedings of IX CBECIMAT, Águas de São Pedro /SP, (1990), p. 546.

[12] W. A. Monteiro, M. A. G. Silveira e O. Júlio Jr: Metalurgia \& Materiais Vol. 51 (1995), p. 440.

[13] W. A. Monteiro, F. Cosandey and P. Bandaru: in Proceedings of THERMEC'97, Wollongong, Australia, July (1997).

[14] W. A. Stadtler Production of Metallurgy Parts ASTM, Powder Metallurgy, Ohio (1989), p.449. 
[15] M. Ghadiri, F.A. Farhadpour, R. Clift and J. P. K. Seville: Particle characterization size and morphology, The Institute of Metals Series on Powder Metallurgy - An Overview. London, (1991), p.56.

[16] Powder metallurgy - An overview. 1. Ed. The Institute of Metals Series on Powder Metallurgy, London, Great Britain, (1991).

[17] W. A. Kaysser: Solid State Sintering. The Institute of Metals Series on Powder Metallurgy - an overview London (1991), p 45.

[18] Thümmler F. and R. Oberacker: Introduction to Powder Metallurgy, The Institute of Materials, (1993).

[19] J. A. G. Carrió, W. A. Monteiro, V. A. Rodrigues, M. C. Terence, T. J.Masson, and L. F. Miranda: European Powder Diffraction Conference - EPDIC 11, 19-22 September, Warsaw, Poland (2008). 